DE DE GRUYTER OPEN
Research Article

(C) 2018 Santos-Roldán et.al.. This is an open access article licensed under the Creative Commons Attribution-NonCommercial-NoDerivs License (http://creativecommons.org/licenses/by-nc-nd/3.0/).

\title{
Tourism as a Support in the Compiling of Data for SMES in the Process of Internationalization
}

\author{
Luna Santos-Roldán \\ Universidad de Córdoba, Departamento de Estadística, Econometría, \\ Investigación Operativa, Organización de Empresas y Economía Aplicada, \\ Facultad de Derecho y C.C.Económicas y Empresariales, Córdoba \\ Beatriz Palacios-Florencio \\ University of Pablo de Olavide, \\ Department of Business Organization and Marketing, \\ Faculty of Business Studies, Carretera Utrera, Seville \\ Corresponding Author

\section{Juan Manuel Berbel-Pineda} \\ University of Pablo de Olavide, \\ Department of Business Organization and Marketing, \\ Faculty of Business Studies, Carretera Utrera, Seville
}

Doi: $10.2478 / \mathrm{mjss}-2018-0023$

\begin{abstract}
Obtaining information is key to business success. However, to achieve this is generally costly (in both monetary and time terms). This is complicated even more for those firms which need information from foreign markets. Moreover, it has to be considered that information based on secondary data is not always available or easy to get, and that to attain it based on primary data requires a great effort. The aim of the present research is to show a procedure which helps SMEs to obtain this market-relevant information. To do so, a new methodology is used which enables these firms to know in broad terms how consumers of the different country-markets behave, as well as getting information related to the product's commercialization. A pilot experience has hence been used, whose target population is tourists in the city of Seville. A sampling session of the product was carried out, via which, and through a questionnaire, information was gathered concerning the countries of origin of the participants in this study. Its flavor is appreciated by the consumer in the four varieties considered, and in appearance, the product also has a very good acceptation. It is worth considering what is going to be the packaging for the product's commercialization and its labeling. The different varieties also have their markets and all of them should be adapted to the local tastes.
\end{abstract}

Keywords: Internationalization, Market Research, Small and Medium-Sized Firm, Network Theory, Tourist

\section{Introduction}

Since the texts of the first economists, international business has always had a leading place in economic theory and practice, especially due to the fact of its importance for a nation's economic welfare and its ensuing development (McGregor 2005).

Every firm interested in expanding beyond the internal market will firstly define its business 
purpose based on the firm's aims and on the country destination (McGowan, Shiu and Hassan 2016). The product's aims will be obtained from the business definition (Jain 2002). In the international market, the product to be exported is made up of intrinsic attributes, external attributes and intangible attributes. The first encompasses the composition, design and quality. The second the labeling and the packaging. The third includes the brand, the image of the country of origin, the guarantees offered and the customer service (Janssen et al. 2016; Baltas and Paraskevas 2007). Nevertheless, first of all entrepreneurs must be sure that their product is exportable, and that it is so by its characteristics, its presentation and all the services and factors which surround it.

The need to obtain information concerning the destination markets is therefore fundamental. And although this does not guarantee success, it at least serves to not fail in knowing how the consumer perceives the product or how the consumer behaves. But to obtain the information required is far from being simple for the firm. Either the information is not always available, or, if it is, it can be costly. This is a significant handicap for SMEs. Even more so, this problem is exacerbated when the information does not exist and the firm itself must obtain it (SMEs do not normally have enough resources to be able to undertake this market research).

The aim of the current work is to show a procedure which helps SMEs to obtain this marketrelevant information at a perfectly affordable cost. To do so, we have worked with a new methodology which enables these firms to know in broad terms how the consumers of the different country-markets may behave and also to gain information related to the product's commercialization. Tourists who visit Spain have been used as a source of primary information. In 2015 Spain was consolidated as the third world power in tourist arrivals (with 68.1 million tourists), after France and the United States. This means that tourism is an important source of contribution to the national GDP $(11.4 \%)$. But we cannot only see the tourists as a source of income. They may also be viewed as a source of information and it is in this sense that they have been considered in the present study.

Based on the above, the structure is developed. First, we cite Network Theory from the perspective of international business. Then, in the methodology, we explain how this study has been carried out, as well as presenting a descriptive account of the sample. Last, we present the results obtained for olives in their four varieties: "Manzanilla" "Spicy Manzanilla", "Gordal" and "Verdial".

\section{Network Theory}

The present article develops a feasible and real synergy between the academic and business world, inspired by Network Theory as a complementary approach to that of Uppsala (Coviello and Munro 1997). The key point for this theory is in the networks of relations between firms (Johanson and Mattson 1988), the level of internationalization being influenced by the degree of internationalization of the firm's network.

Johanson and Mattson (1988) consider business networks to be the relations of firms with their customers, distributors, competitors and government. By means of the interactions between local firms and their networks we reach the foreign market. In essence, what remains in the core of these networks is the transfer of and access to information. That is, an exchange between firms with complementary resources and information stemming from their experiences through a social interaction.

Therefore, the network approach, with its emphasis on the role and influence of other actors direct and indirect, formal and informal - analyzes the balance of the firm's competitive advantages and those which stem from the members of the network in which the firm is located. Internationalization with this in mind depends more on the interweaving of relations, as well as maintaining them over time.

Networks are especially attractive for SMEs interested in exporting. Given their limited resources, most of them depend on a single product. This is why knowledge is fundamental in the identifying of new market opportunities in different countries where their product and the entry form are accepted. The importance of contact networks is justified by the trust transmitted by their mediation, their proximity (starting with the local market which has an easier access) and the 
increase of knowledge of other markets. Knowledge is considered to be basic for its relevance in selecting foreign markets, and through collaborations between the academic and the business world firms can be provided with specific information services to be able to adopt their decisions with greater safety. This is a process which is fed back, improving the position in the network as the knowledge increases (Schweizer, Vahlne and Johanson 2010). This combination makes SMEs take a further step in the challenge of opening to foreign markets.

Within a network there will be a disparity of benefits between its components, such as a singular access to information for the members which have exclusive links with distant groups. From this perspective, to know the opportunities offered by the foreign markets depends on each member's particular benefits from the social network. Furthermore, there will be an additional gap between the different networks. Those which are larger and more diverse will have more opportunities. Also, as the degree of internationalization increases, the same thing will happen with the number of actors with which they have to interact through the network (Trujillo, Rodríguez and Guzmán A Becerra 2006).

Finally, another group of works have admitted that one of the factors which transforms a classic firm into one that is born global is the development of their relations and the obtaining of their maximum benefit. Numerous authors have studied the variables which favor the emergence of born global firms. From this perspective, we highlight two promoting factors: a greater specialized knowledge (McDougall, Shane and Oviatt 1994; Dimitratos and Jones 2005; Evangelista 2005) and larger social networks (Coviello and Munro 1995, 1997; Harris and Wheeler 2005; Loane 2006).

\section{Methodology}

As has been shown, this work's aim is to compile information about foreign markets (from that supplied by tourists who visit the city of Seville), which helps in the internationalization process. To do so, we used a pilot experience, via which, taking these tourists as a target population, we carried out a sampling session of the organoleptic tasting of four varieties of olives: "Manzanilla" "Spicy Manzanilla", "Gordal" and "Verdial". Through a questionnaire, we gathered information concerning the country of origin of the participants in this study and of their shopping and consumption habits.

This has meant that, practically cost fee, the firm which commercializes ecological olive oil ${ }^{1}$ has been able to obtain valid information which helps them to know some aspects required in their internalization process.

The study was carried out over three days in a space at the firm's disposal in the center of Seville. The firm (via its staff) had its product tested and offered all the information required by the tourist taking part in the study. Following the organoleptic tasting, those in charge of the project (with the support of the firm's staff), compiled the information that the person provided (via a questionnaire). Generic information was obtained after the tasting and a sample of the product and a pendrive were given out.

A double investigation treated the data collected: qualitative and quantitative. To do so, three prior meetings took place between the firm's staff and those in charge of the study in order to agree on and validate the questionnaires. After this certification, we proceeded to the quantitative research (Table 1 shows the work sheet).

Table 1: Technical sheet

\begin{tabular}{|l|l|}
\hline Firms taking part & Ecological olive oil \\
\hline Participants & 354 (112 men and 242 women) \\
\hline $\begin{array}{l}\text { Nationalities } \\
\text { represented }\end{array}$ & $\begin{array}{l}\text { Australia, Belgium, Brazil, Colombia, Costa Rica, Cuba, Czech Republic, Ecuador, } \\
\text { Germany, Finland, France, Haiti, Ireland, Italy, Mexico, Peru, Poland, Portugal, } \\
\text { Slovakia, Ukraine, United Kingdom, United States, }\end{array}$ \\
\hline
\end{tabular}

Source: own elaboration.

\footnotetext{
${ }^{1}$ The brand name has been kept confidential due to the firm's express request.
} 
Out of the total of 354 participants, a clear predominance of women was noted- $68.4 \%$ compared to $31.6 \%$ of men.

A success factor of the sample obtained is the diversity of the countries of origin. The information compiled is evidence of the wide range of countries present: 24 . To facilitate the processing of this information, we considered it appropriate to group together those countries which had less people. We then had a classification of 8 groups: Latin America (Brazil, Colombia, Costa Rica, Cuba, Ecuador, Haiti and Peru); Mexico; the United States; Central Europe (Germany, Austria, Belgium and Holland); geographically close markets (France and Portugal); Italy; Eastern Europe (Slovakia, Ukraine, the Czech Republic and Poland ); and lastly, a section of "others" where we have included those territories which have a lower representation (Finland, Ireland and the United Kingdom), or with a less close geographical coherence (Australia). They are represented in the following way:

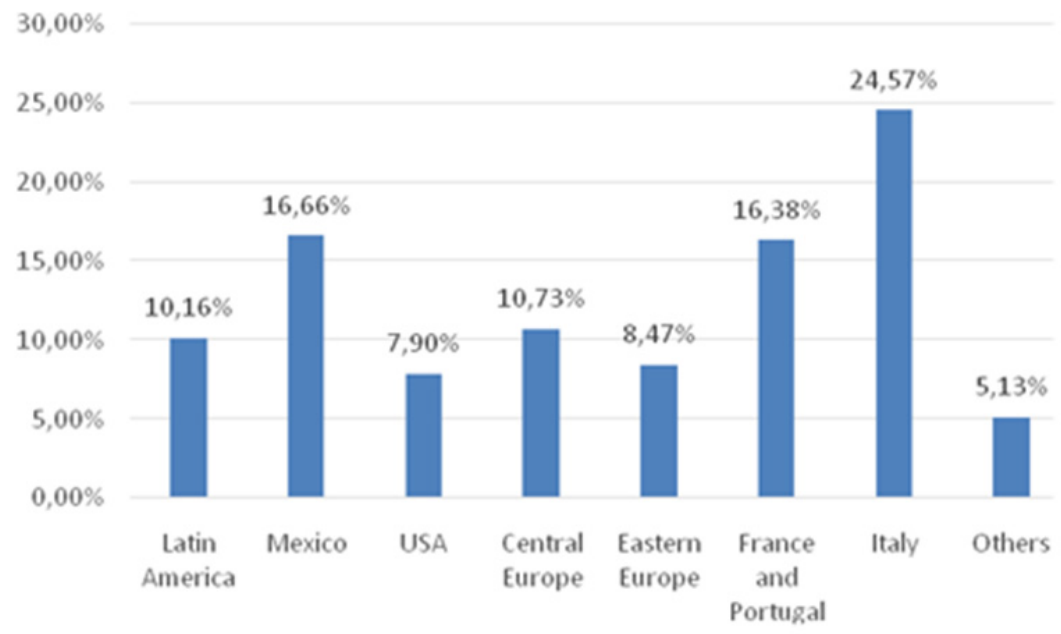

Figure 1: Markets represented(\%)

Source: own elaboration.

\section{Analysis of the results}

The current situation of the agroalimentary sector clearly presents a scenario in which the drop in prices and the fall of consumption stemming from the economic crisis and the asymmetries of the producers compromises their survival. The search for a greater dimension through different cooperation processes and internationalization are alternatives which may enable small producers to maintain themselves in the market.

We know that table olives are one of the most traditional foods of the Mediterranean diet, but they are also consumed in numerous other countries as an aperitif, snack or starter.

Questions were asked about the shopping and consumption habits, knowledge and opinion of Spanish cooking and other relevant questions, as well as specific questions about olive products. Specifically, the first characteristic to be analyzed was the flavor of the product. Although it is difficult to measure (due to its subjective nature), we have established a series of items from the information provided on the product's label, from its tasting and from the information given by the entrepreneurs present in this market research. Along with this, we evaluated the characteristics of the product's appearance and its adaptation to the country's preferences. These were evaluated via a 10-point Likert scale which moved upward, the maximum positive value being 10 . 


\subsection{Flavor}

Regarding the flavor, "Manzanilla" was given 7 points by $18.1 \%$, this being the most repeated score. Most of the tastings of this kind of olive placed its flavor as being very favorable. $42 \%$ of them rated it with a score greater than 7 (that is to say, 8,9 or 10), with $15.9 \%$ of the tasters giving it a score of 10 points.

"Spicy Manzanilla" got one point more $-20.4 \%$ of those interviewed rated it with an 8 . Although the previous variety of olive was placed with a very favorable score according to the taste of those interviewed, "Spicy Manzanilla" was the winner of this study and $57 \%$ gave it a score over 7 , and $36.5 \%$ of the tasters considered it excellent and gave it 9 or 10 points.

"Gordal" was given a 9 by $19 \%$ of its stand's visitors - another variety which is attractive and whose flavor satisfied those interviewed. Again $50 \%$ valued it as more than favorable, with a score over 7 points.

$20.1 \%$ of the tasters classified "Verdial" with 8 points. $45.45 \%$ gave it more than a $7,25.4 \%$ giving it a 9 or 10 . Although it was in no way worrying, this variety is the one which had the highest percentage of visitors who did not like its flavor $-10.4 \%$ giving it a 3 . This is the highest percentage in comparison with the rest of the people who did not like the flavor of the four types of olives; that is to say, those who qualified them under 5.

Following this line, we analyzed which type of olive did not satisfy and is given values lower than 5 on the whole. The information obtained is similar in "Manzanilla", "Gordal" and "Verdial"$19 \%$ of the people did not like the flavor, while we drop to $14.5 \%$ for "Spicy Manzanilla".
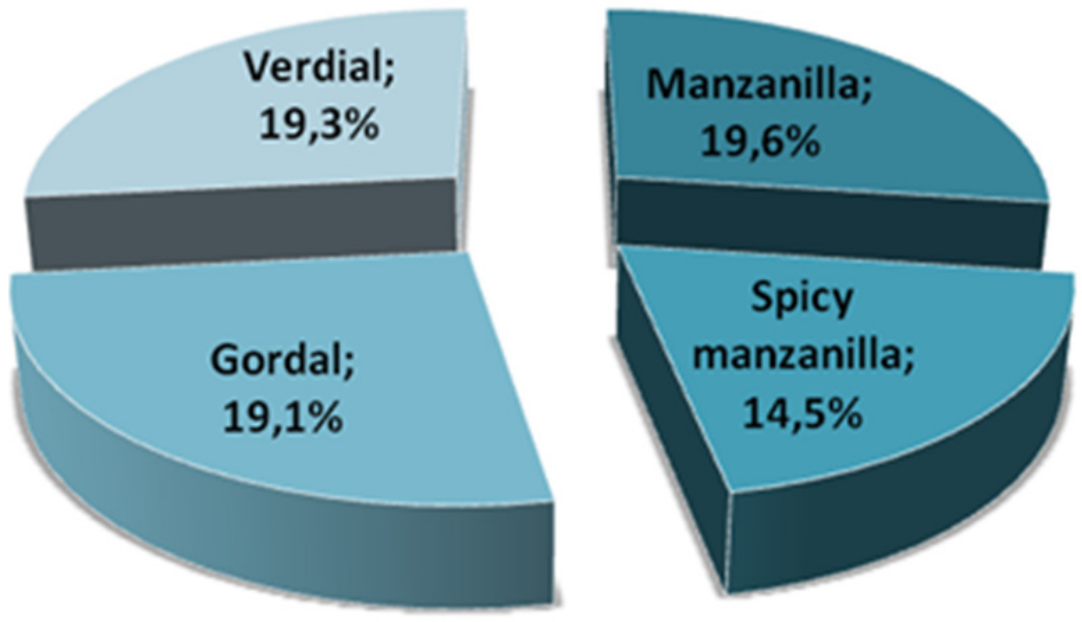

Figure 2: Percentage of tasters not satisfied with the flavor (\%)

Source: own elaboration.

We note that the variable "flavor" for the four varieties has been appreciated with more than acceptable values, obtaining qualifications of good or excellent. It follows that the foreign consumer is in general aware of the quality of the product of Spanish olives and, what is equally important, they appreciate its good taste.

\subsection{Appearance}

Referring to appearance, Graph 3 shows the information compiled from the four varieties. 


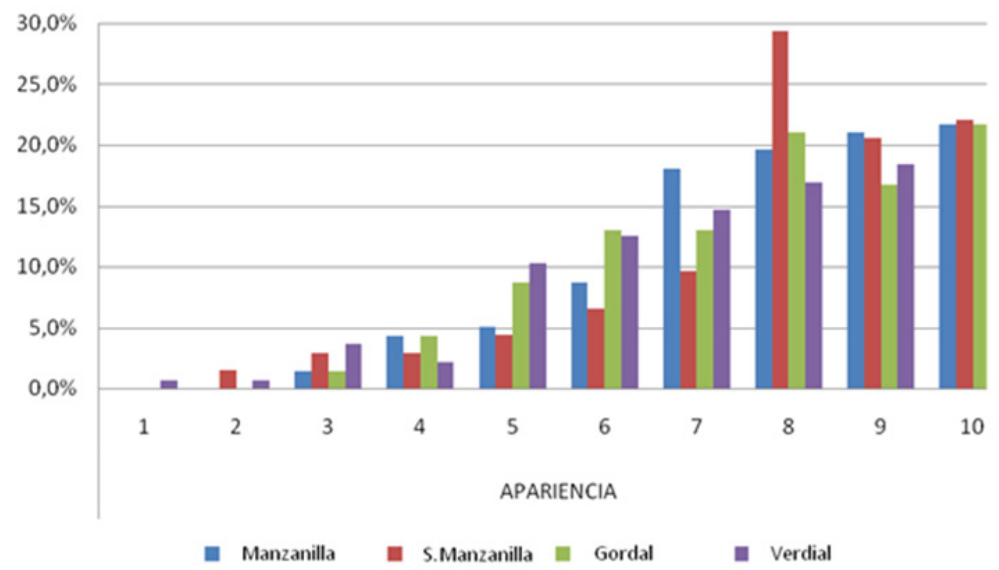

Figure 3: Bars of scores related to the Appearance of the four olives (\%)

Source: own elaboration.

As a generalized guideline, the tasters favorably valued the aspect of the olives. The highest percentage for "Manzanilla" was $21.7 \%$ who gave it a 10 . For "Spicy manzanilla", the highest percentage was $29.4 \%$ with a value of 8 . "Gordal" got $21.7 \%$ with a value of 10 . Finally, "Verdial" has a maximum percentage of $19.9 \%$ giving it a value of 10 . The spike perceived in the level of 8 of "Spicy Manzanilla" is not inconsistent with the general satisfactory trend commented on in this section and is very probably the fruit of a link with appreciating its flavor. In the main, significant differences are not considered in this variable between the different types of olives, all of them being well valued. This is to be expected given the little difference (especially for a foreign consumer) of shape, size and color (except perhaps for the distinctive orange undertone more evident in "Verdial" olives).

\subsection{Adaptation of the product to the country's preference}

Another relevant aspect to be analyzed was how the different flavors of the product were adapted to local tastes. That is to say, we intended to know what was the generic level of adaptation to the tastes of the different consumers. To do so, we used a 5-point Likert scale (from 1: "very little" to 5: "a lot"). The results are shown in the following graph and the percentage figures are set out in the table which follows:

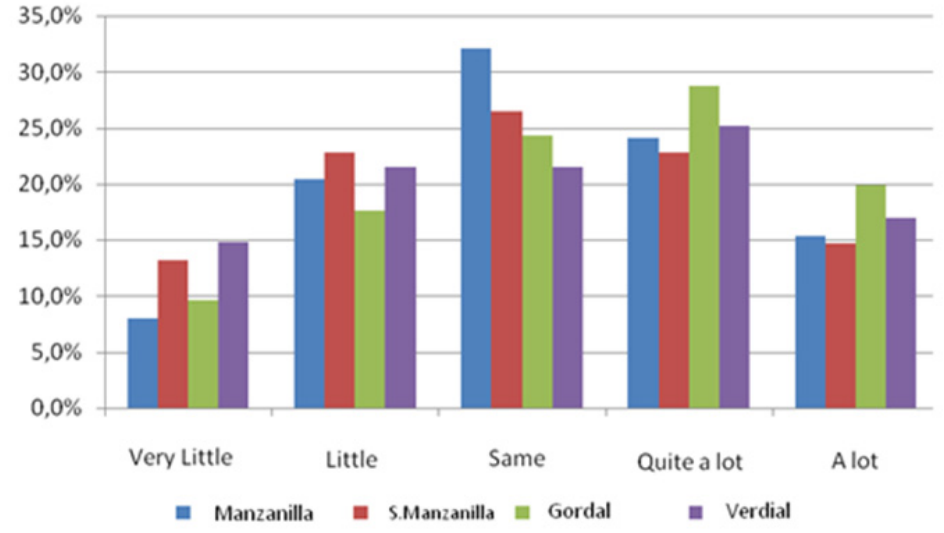

Figure 4: Adaptation of the Flavor to Local Tastes (\%)

Source: own elaboration. 
Table 2: Percentage of scores related to adapting to the olives

\begin{tabular}{|l|c|c|c|c|}
\hline Adaptation to the flavor of local tastes \\
\hline & Very little & Little & Same & Quite a lot \\
\hline Manzanilla & $8.0 \%$ & $20.4 \%$ & $32.1 \%$ & $24.1 \%$ \\
\hline Spicy manzanilla & $13.2 \%$ & $22.8 \%$ & $26.5 \%$ & $22.8 \%$ \\
\hline Gordal & $9.6 \%$ & $17.6 \%$ & $24.3 \%$ & $28.7 \%$ \\
\hline Verdial & $14.8 \%$ & $21.5 \%$ & $21.5 \%$ & $25.2 \%$ \\
\hline
\end{tabular}

Source: own elaboration.

It can be seen how in this section there is more of a spread and not so much uniformity. On the one hand, a similarity of tastes is indicated in the countries of origin in the cases of "Manzanilla" and "Spicy manzanilla"; on the other hand, it is typical of the tastes of the country in the cases of "Gordal" and "Verdial". The diversity of data is a characteristic of the broad range of countries represented by the participants in the tasting and we will later go thoroughly into a study of them.

We consider a disaggregated approach very interesting for this report; that is, for each of the markets established we have determined their order of preference with respect to the different types of olives. To examine this, we carried out an investigation about the preference of taste, its order and the percentage of the population which defended each flavor preferred, at the level of the different markets into which the sample was divided. We see the result in the following graphs (the values are in percentages).

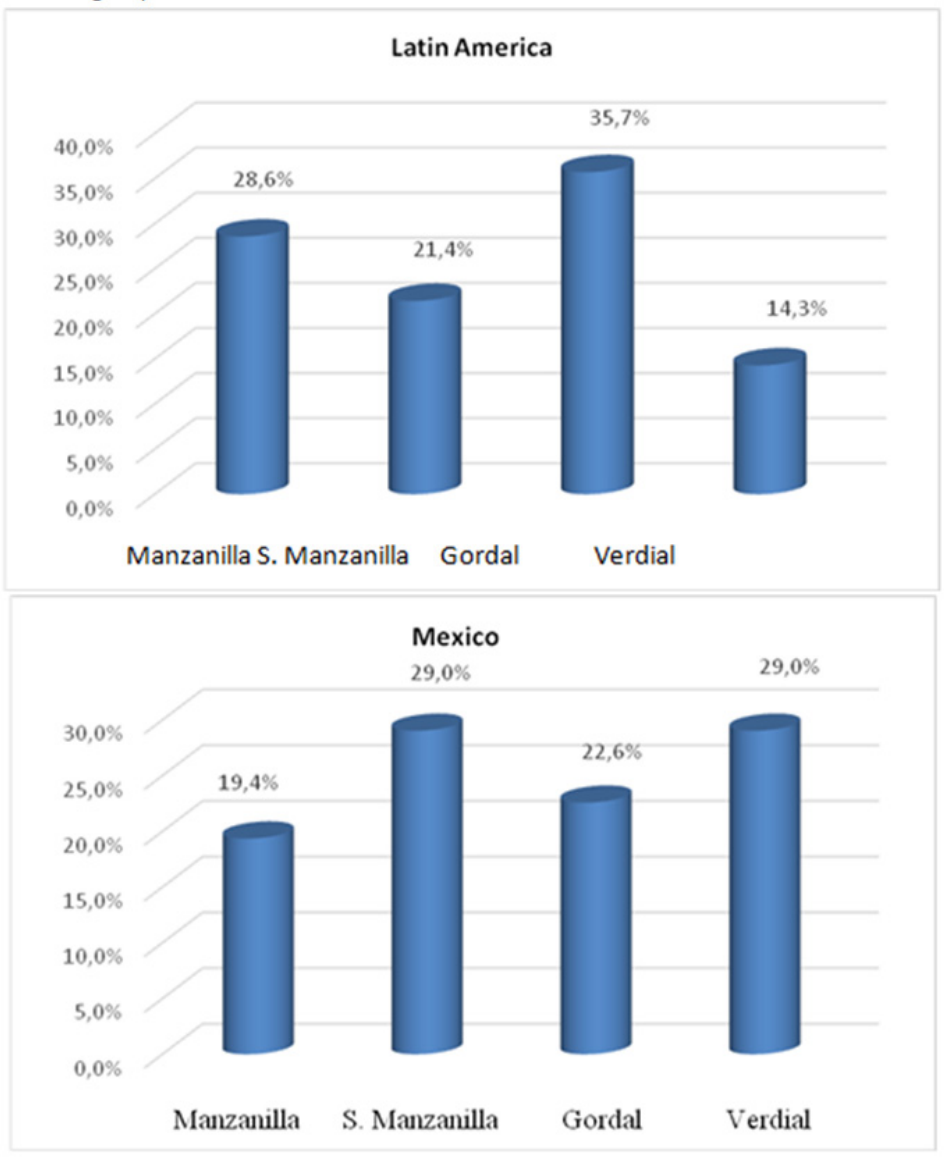



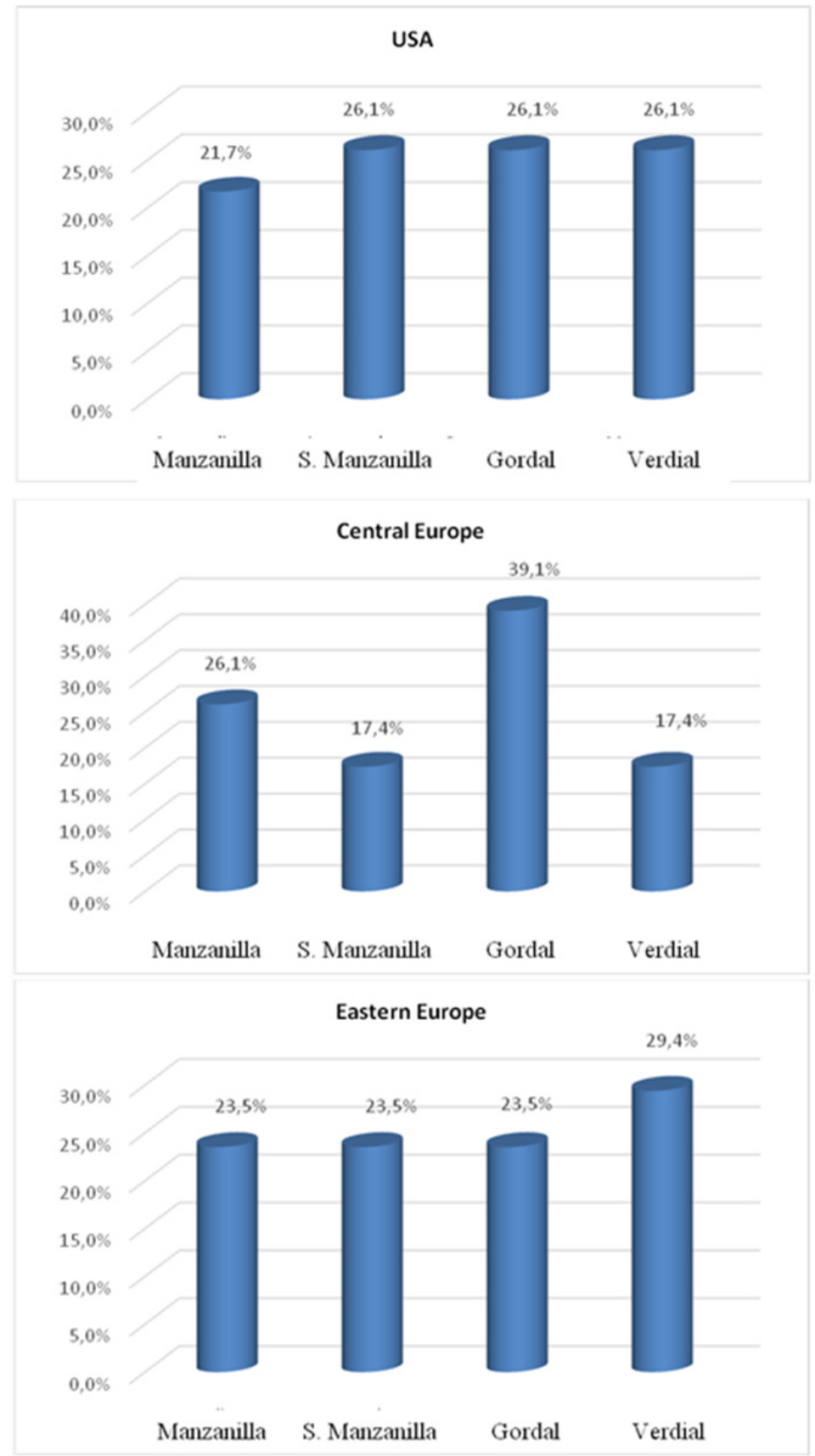


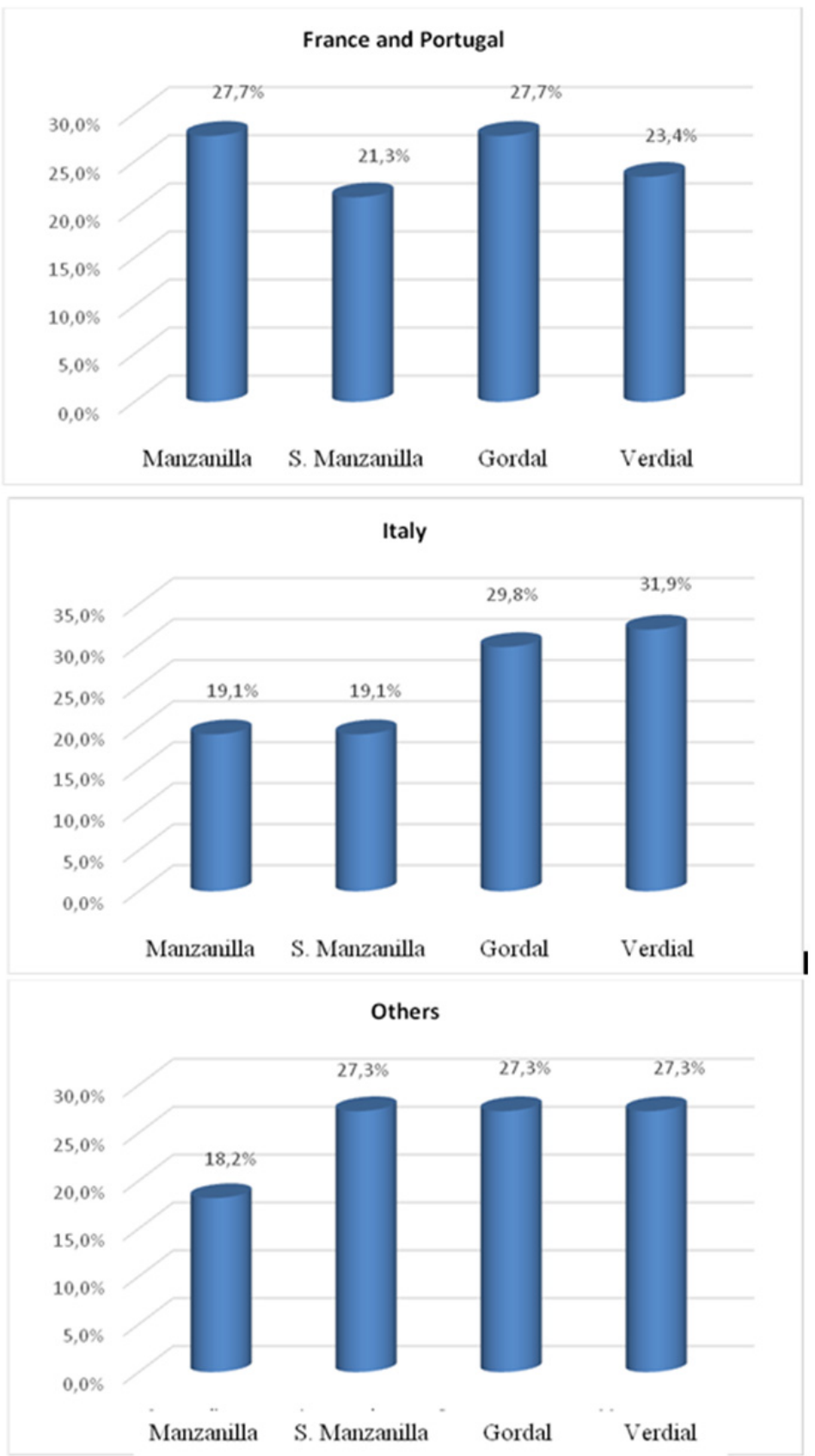

Figure 5: Tasting Trends by territories (\%) Source: own elaboration.

It can be seen that by territories "Gordal" is the most accepted flavor in Latin America. In Mexico this is "Spicy manzanilla" and "Verdial". In the USA, the most appreciated flavors are, equally, "Spicy manzanilla", "Gordal" and "Verdial". In Central Europe a better score is given to "Gordal", 
while in Eastern Europe this is given to "Verdial". In France and Portugal (close markets) "Manzanilla" and "Gordal" have the best acceptation; in Italy "Verdial" (followed closely by "Gordal"). Finally, in the group which we called "Others", the varieties of "Spicy manzanilla", "Gordal" and "Verdial" are equally appreciated.

\subsection{Frequency of consumption}

Next, we wanted to know to what extent this product was consumed by the interviewee. That is to say, we wanted to know its frequency of consumption. To do so, we recurred to a 5-point Likert scale, with the following values: "I do not tend to consume it", "once a week", "several times a week", "once a day", "several times a day", marking the consumption of the product from less to more.

In this analysis of frequency of consumption, we estimate that there could be differences of consumption if the same question was asked about the frequency of consumption in Spain (the majority of the interviewees were people who had been in Spain between a month and eight months).

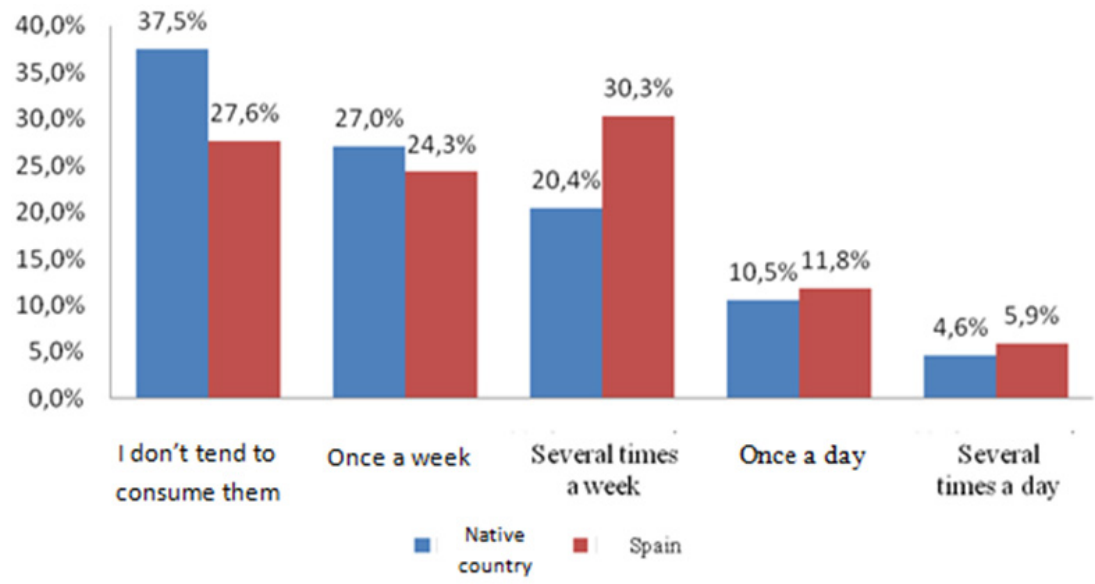

Figure 6: Frequency of consumption

Source: own elaboration.

The results show that in general this product is not consumed a lot by the respondents $(37.5 \%$ never consume olives in their country), and $27 \%$ of the respondents consume them little (once a week). At the other extreme, we note that around $15 \%$ of the respondents can be defined as loyal consumers of the product, eating them once a day or several times a day in their countries of origin.

Nevertheless, it is seen that its consumption in Spain is higher than that in their respective countries, with $18 \%$ of loyal consumers eating them once a day or several times a day. The majority $-30.3 \%$ - state that during their stay in Spain they ate olives several times a week. For many of these consumers this has been the first time that they have tried them and it can be expected that they will become consumers on their return.

\subsection{Competition}

The study of the competition is an aspect that this study could not avoid covering. To do so, we asked if they knew competing products and which competing brands they knew in their countries (it was made clear to the respondents which competing brands similar to that tested, as to its essential characteristics, were commercialized there).

In this case, $81.8 \%$ of the participants in the work made it known that they knew of there 
being competing products in their countries. Given this high response percentage, we asked about them. The brands which we show in the following figure were those mentioned by the interviewees, those at the base of the pyramid being the most repeated.

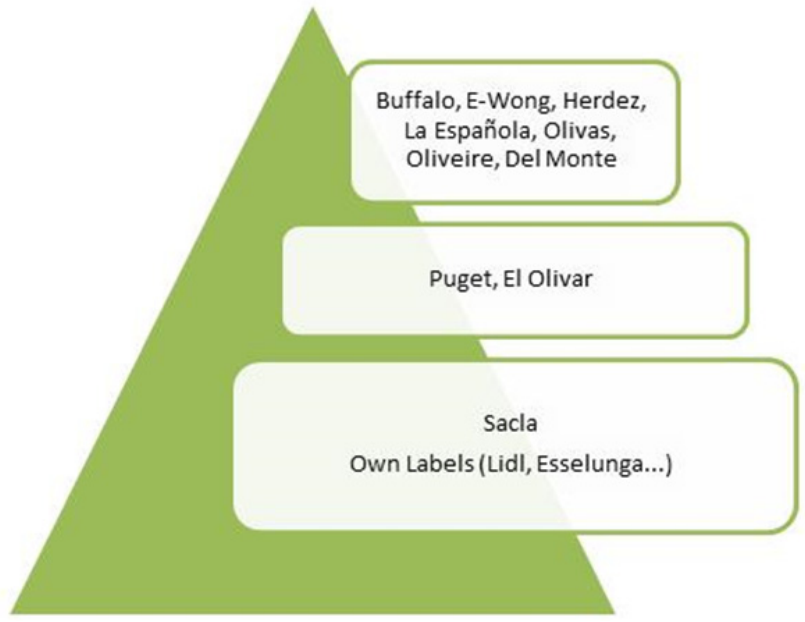

Figure 7: Identification of the competitors

Source: own elaboration.

A certain confusion was noted about the category of the product and with other brands of a quality/lower price relation, but this reflects the lack of education of the consumer and the need to educate their consumption with respect to quality olives.

\section{General valuation and conclusions}

Lastly, they were asked for a general valuation of the product that they had just tried. To do so, a 5point Likert scale was used: "very bad", "bad", "average", "good", "very good". In this case, about the "olive" product (without particularly distinguishing the flavor), the valuation was very positive. Around $75 \%$ of those interviewed gave a valuation of "good" and "very good" (it stands out that only $2 \%$ of the valuations were "very bad"). It is therefore a product that is very well valued by consumers.

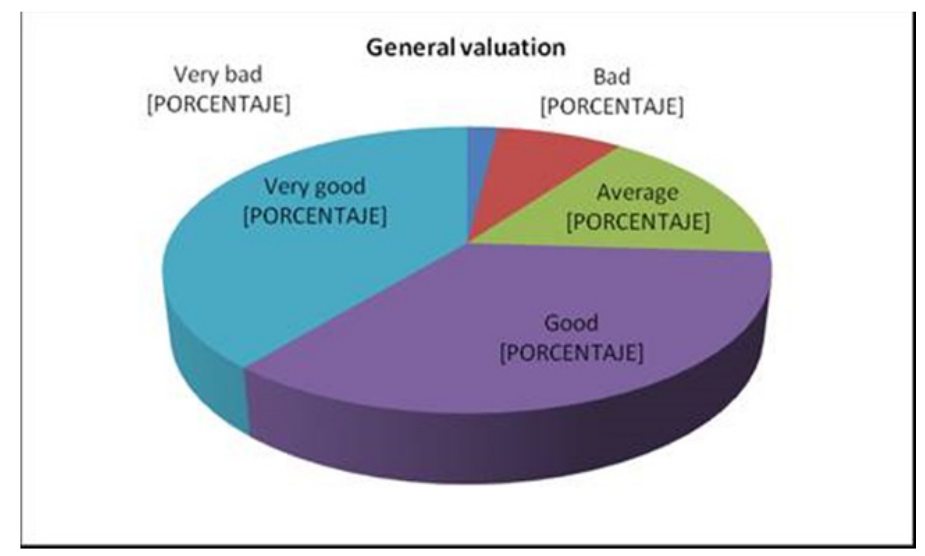

Figure 8: General valuation

Source: own elaboration. 
As a general summary of this product, we can say that its flavor is appreciated by the consumer in the four varieties considered. In appearance the product also has a very good acceptation. It is worth considering what is going to be the packaging for the product's commercialization and its labeling, adapting both to the preferences of each territory and conceived so as each of the different varieties is better differentiated.

The different varieties also have their markets and all of them should be adapted to the local tastes (there is no variety which notably shocks the tastes of the different markets). All this has to be considered within the context of this product. Though it is consumed in numerous territories, olives tend to elicit extreme reactions, with certain consumers rejecting such a particular and penetrating flavor, while others enjoy it and tend to be loyal consumers.

\section{References}

Coviello, N., and Munro, H. 1997. "Network relationships and the internationalization process of small software firms". International Business Review 6(4): 361-386.

Dimitratos, P., and Jones, M.V. 2005. "Future directions for international entrepreneurship research". International Business Review 14(2): 119-128.

Evangelista, F. 2005. "Qualitative insights into the international new venture creation process". Journal of International Entrepreneurship 3(3):179-198.

Harris, S. and Wheeler, C. 2005. "Entrepreneurs' relationships for internationalization: function, origins and strategies". International Business Review 14: 187-207.

Jain, S.C. (2002). Marketing internacional. Ed. Thomson: Mexico.

Janssen, L., Fransen, M., Wulff, R., and Van Reijmersdal, E.A. 2016. "Brand placement disclosure effects on persuasion: The moderating role of consumer self-control". Journal of Consumer Behaviour 15: 503-515.

Johanson, J., and Mattsson, LG. 1988. "Internationalisation in industrial systems - A network approach". In: Hood N. Vahlne J.E. Editors, Strategies in global competition, Croom Helm: London.

Loane, S. 2006. "The role of the internet in the internationalization of small and medium sized companies". Journal of International Entrepreneurship, 3: 263-277.

McDougall, P., Shane, S., and Oviatt, B. 1994. "Explaining the formation of international new ventures: the limits of theories from international business research". Journal of Business Venturing, 9(6): 469-487.

McGregor, S. 2005. "Consumer transactions with SMEs: implications for consumer schoalrs". International Journal of Consumer Studies, 29 (1): 2-16.

McGowan, M. Shiu, E. and Hassan, L. 2016. "The influence of social identity on value perceptions and intention". Journal of Consumer Behaviour.

Schweizer, R., Vahlne, J.E. and Johanson, J. 2010. "Internationalization as an entrepreneurial process". Jounal of International Entrepreneurship, 8(4): 343-370.

Trujillo, M.A., Rodríguez, D.F., and Guzmán A Becerra, G. 2006. Perspectivas teóricas sobre la internalización de empresas. Editorial Universidad Rosario: Bogota D.C.

Baltas, G., and C. A. Paraskevas. 2007. "Consumer Characteristics and Demand for Store Brands." International Journal of Retail and Distribution Management 35 (5): 38-41. 